\title{
Bone quality and quantity are mediated by mechanical stimuli
}

\author{
Alycia G. Berman ${ }^{1}$ and Joseph M. Wallace ${ }^{1,2}$ \\ ${ }^{1}$ Department of Biomedical Engineering, Indiana University Purdue University of Indianapolis \\ ${ }^{2}$ Department of Orthopedic Surgery, Indiana University School of Medicine and Indianapolis, IN, United \\ States.
}

Send Correspondence to:

Joseph M. Wallace, PhD

Department of Biomedical Engineering, SL 220D

723 West Michigan Street

Indianapolis, IN 46202

Tel: $317-274-2448$

FAX: 317-278-2455

Email: jmwalla@iupui.edu

\begin{abstract}
Prevention of fracture through improved bone mechanical strength is of great importance given the large number of bone disease-related fractures each year, the decreased quality of life associated with fractures, and the large anticipated increase in fracture incidence over the upcoming years due to the aging population. Exercise and other forms of mechanical stimulation have been shown to increase bone mass, suggesting improved strength. However, while bone mass is a good indicator of strength, other components (such as bone quality) also contribute to bone mechanical integrity. While increased bone mass has been explored considerably using both exercise and targeted loading models, the role of mechanical stimulation in altering bone quality has been explored to a lesser degree. Understanding how to improve both the quantity and quality of bone is critical to increasing fracture resistance. Herein, we discuss quantity and quality-based improvements that have been observed using both exercise and targeted loading models of bone adaptation.
\end{abstract}

Keywords: mechanical adaptation, bone quality, exercise, targeted loading, mechanical stimulation

This is the author's manuscript of the article published in final edited form as:

Berman, A. G., \& Wallace, J. M. (2016). Bone Quality and Quantity are Mediated by Mechanical Stimuli. Clinical Reviews in Bone and Mineral Metabolism, 14(3), 218-226. https://doi.org/10.1007/s12018-016-9221-5 


\section{HISTORICAL PERSPECTIVE AND CLINICAL SIGNIFICANCE OF BONE RESPONSE TO MECHANICAL STIMULATION}

Throughout the course of a lifetime, a person's bones are constantly loaded and unloaded, whether that be through walking, running, bending over, standing up, etc. As is true for any structure and material, constant loading of bone can lead to fatigue of the bone tissue and can cause accrual of damage, resulting in a weakened bone. In order for bone to maintain its mechanical integrity, it must be a dynamic structure, one that is able to repair itself and to adapt to the loads engendered on it. The goal of this review is to focus on this adaptability of bone, particularly from the perspective of the effects of mechanical loading on bone material properties.

This concept that bone responds to mechanical stimulation is not new. Although Julius Wolff is often credited with the idea (commonly referred to as Wolff's Law due to his 1870 publication [1]), the notion that mechanical loads influence the structure and organization of bone was observed well before, back to at least the 1830s when three doctors described their observations regarding trabecular organization [2]. Their observations were rather simplistic, and so perhaps, the true credit for the concept should be given to Georg Hermann von Meyer [3] who wrote a seminal work in 1867 on the idea that trabeculae are arranged in a specific manner which tended to align with the principal stress trajectories in bone. Hermann von Meyer was later followed by Karl Culmann, a mathematician who noted that the alignment of trabecular bone tended to follow a mathematical pattern seen in "graphic statics." In the late 1800 s, Wolff referenced von Meyer's and Culmann's works in the creation of his paper, where he discussed the adaptation of trabeculae to load, which eventually came to be known as Wolff's law and is often used as the key reference for the mechanical adaptability of bone.

Effectively, Wolff's law states that bone will adapt to the loads engendered on it. In other words, the trabecular structure of bone is precisely arranged to place bone where it is needed and remove bone that is not needed in order to maintain structural integrity. Over a hundred years later, in 1987, Harold Frost [4] 
published a conceptual model on bone adaptation, called "The Mechanostat," in which bone itself was seen as a negative feedback system that would respond with either formation or resorption, depending on the local strain field. At almost the same time, Rubin and Lanyon began publishing on a similar idea whereby adaptive remodeling was sensitive to changes in both the magnitude and distribution of strain in bone [5].

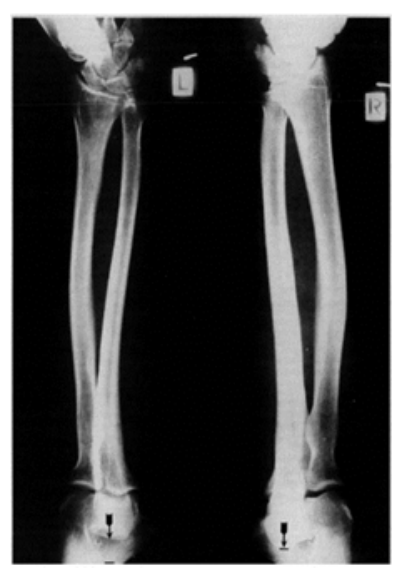

Fig. 1 As is the case for cancellous bone, cortical bone also adapts to its mechanical environment. Take the case of an elite tennis player. In the radiograph of the forearm, the dominant arm (right side in the figure) has a much larger cortex than the contralateral arm, presumably due to the increased forces acting on the dominant arm during tennis. Figure used with permission from SAGE Publications [6].

This response of bone to mechanical stimulation has been observed in many human exercise studies [7]. A common example is found in tennis players who, due to the forces of impact and muscle loading, often have increased bone mineral content in their dominant arm as compared to their non-dominant arm, as shown in Fig. 1 [8]. Similarly, the throwing arm of baseball players has been shown to have increased bone mass and improved structure as compared with the non-throwing arm [9]. Running [10-12], jumping [13], gymnastics [14, 15], weight lifting [16], and swimming [17, 18] have all been shown to increase bone mass as compared to sedentary controls. This bone mass response seems to be dependent on the degree to which the activity is weight bearing $[19,20]$, as well as the starting age, with pre-menarche girls having the greatest increase in bone mineral content [21]. 
Just as mechanical stimulation can increase bone mass, a decrease in mechanical stimulation (through disease or disuse) can cause a relatively rapid decrease in mass. This decrease can be seen as the bone trying to balance the need for strength with the metabolic costs associated with maintaining that strength. Bone is a dense structure in comparison to almost all other tissues in the body such as fat, muscle and skin (nearly double the mass per unit volume) and has large metabolic needs. In situations of disuse, bone loss will occur quickly because the body no longer needs to metabolically support such a large structure for load bearing ability [22]. A common example is astronauts, who often experience bone loss due to microgravity while in space [23-26]. In a study of long-duration flights (average duration approximately 6 months), almost all long-duration astronauts experienced at least a 3\% bone loss in at least one skeletal site, while $43 \%$ showed at least a $10 \%$ bone loss in at least one skeletal site [27]. In fact, the decrease in bone in astronauts was found to be approximately $1-1.5 \%$ per month [28], and was shown to be up to $2.7 \%$ per month in the trabecular region of the femoral neck [29]. Astronauts are not the only ones affected. Bedrest is often used as a model of space flight [27], as it has been shown to decrease bone density by approximately $0.3-1 \%$ per month $[30,31]$. In addition, diseases such as osteoporosis are thought to be caused, at least in part, by a failure of bone cells to respond to mechanical stimulation [32]. This bone loss (through space flight, bed rest, osteoporosis, or another mechanism) decreases the skeleton's ability to bear load and can lead to fracture in instances of high impact loading (such as falling).

Prevention of fracture through improved bone mechanical strength is of great importance given the large number of bone disease-related fractures each year, the decreased quality of life associated with fractures, and the large anticipated increase in fracture incidence over the upcoming years due to the aging population [33]. For this reason, much research has been dedicated to understanding how and why bone responds to mechanical load. In addition to clinical studies, the use of pre-clinical animal models has aided greatly in advancing our knowledge on the response of bone to mechanical stimulation.

\section{ANIMAL MODELS OF MECHANICAL STIMULATION}


While clinical studies have provided clear indications that bone adapts to mechanical stimulation, most of our understanding of the specifics of how and why bone adaptation occurs have been derived from studies using pre-clinical animal models. In general, in vivo animal models of mechanical adaptation can be divided into exercise-based or targeted loading modalities.

Exercise, as the name would suggest, refers to loading modalities such as treadmill running [34, 35], jumping [36], swimming [37, 38], and climbing [39, 40]. Exercise models tend to be non-invasive, where loading of bone is delivered through muscle contraction and ground reaction forces. In exercise models, the entire animal is affected which makes these models physiologically relevant. The main limitation, however, is the incomplete control over the mechanical inputs to the bone, which can be dependent on each individual animal's activity and activity level, body weight, etc. It is also difficult to isolate the influences of mechanical loading from those that result from the whole body response.

In contrast, targeted loading provides an alternative means of assessment in that a known load or strain stimulus can be applied to all animals in a consistent manner. A variety of targeted loading models are shown in Fig. 2. In most cases, a single limb or single bone is mechanically stimulated. The earliest experiments were somewhat invasive, using implanted surgical pins [41], four-point bending of the tibia [42], or cantilever tibial loading [43]. While studies using these models were certainly important and informative, surgical implantation or the direct application of loading on the bone's surface can lead to confounding effects including inflammation and woven bone formation. More recently, these models have mostly been abandoned in favor of ulnar loading [44, 45] and tibial loading [46] which are cheap and relatively simple to employ and do not suffer from the same limitations mentioned above. Most studies have shown that adaptation of both cortical and cancellous bone are confined to the loaded limb [47], thus enabling the animal's contralateral limb to act as an internal, non-loaded control. However, caution should be exercised as there is some evidence that systemic effects of loading at remote skeletal sites do exist in these models $[48,49]$. 

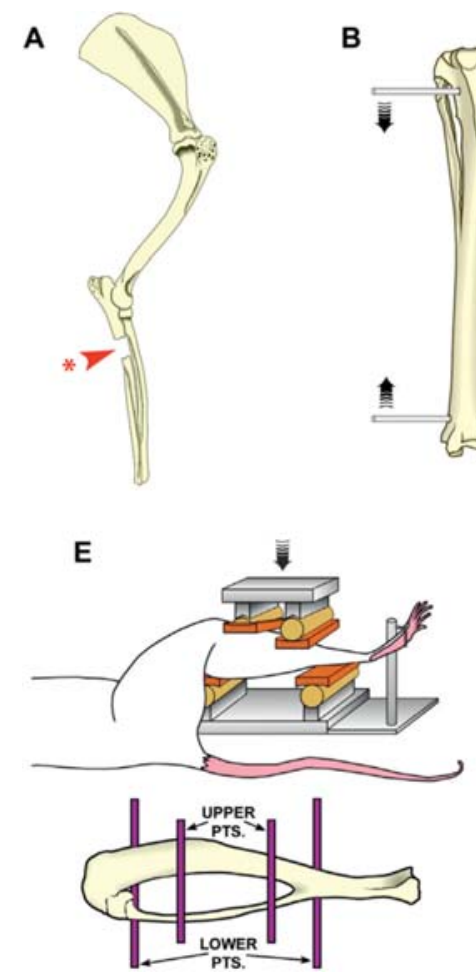

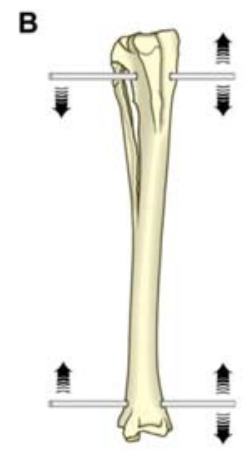

$\mathbf{F}$

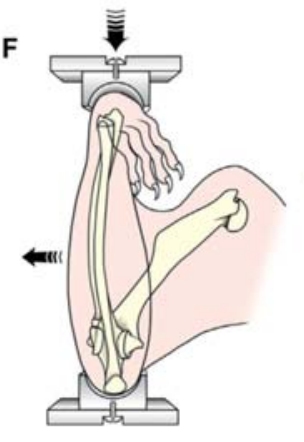

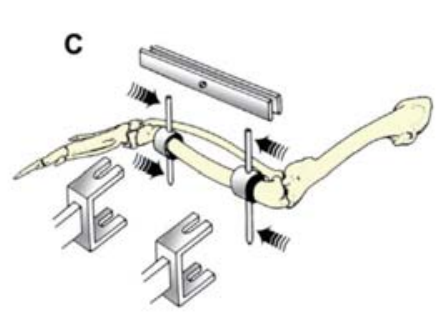
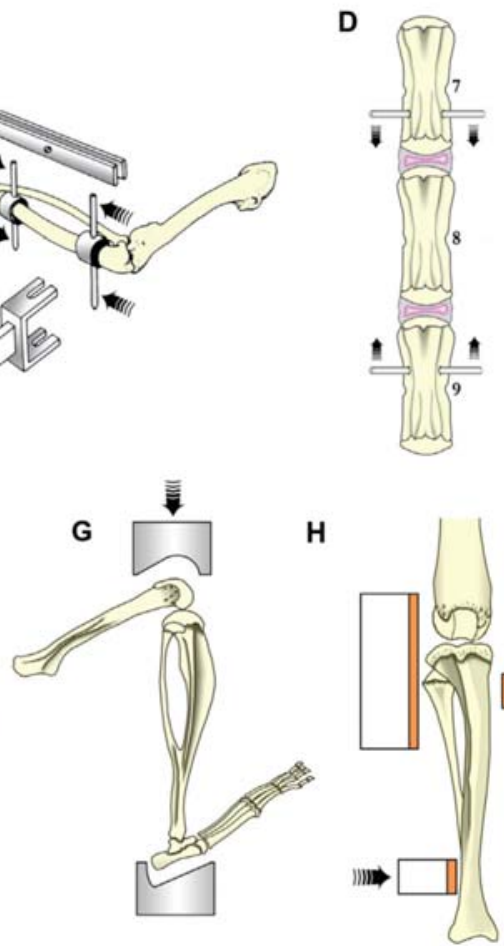

H

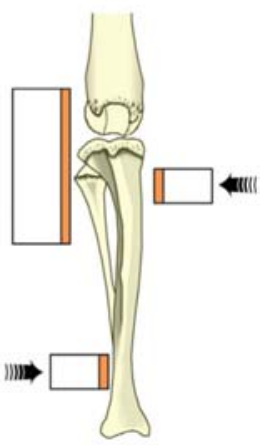

Fig. 2 Targeted loading models apply force to a single limb or bone, thus allowing greater control over the mechanical stimulus applied. A variety of targeted loading models have been employed, including a) osteotomy, b) use of surgical pins in the rabbit tibia, c) turkey ulna, and d) rat caudal spine. Non-invasive models have also been developed, including e) rat four-point tibial loading, f) rat ulnar loading, g) axial compressive tibial loading and h) cantilever bending of the tibia. Figure used with permission from Elsevier Publishing Company [50].

\section{Extrinsic Factors Influencing Bone Formation Response}

Both exercise and targeted loading have significantly advanced our understanding of what triggers a bone formation response. For example, the strain stimulus during loading must be above a certain threshold [51] and the loading must be dynamic (not static) [52] in order for bone to respond. The threshold was later found to be location dependent, and it was demonstrated in the rat ulna that the threshold strain was higher in areas that were regularly subjected to larger in vivo mechanical strains [53]. Once above that strain, bone formation responds more or less linearly to the amount of strain engendered [51,54, 55]. Strain 
rate also has an impact, with high strain rates resulting in higher bone formation rates while static loads had no effect $[52,56,57]$. In most studies, inserting rest into the loading bouts can also increase the bone formation response [58-60]. The cellular mechanisms governing this observation are not altogether clear, but it is thought to involve the modulation of intracellular levels of calcium in osteoblasts [61], or potentially the movement of fluid through the canilicular network and around osteocytes with rest allowing for the relaxation of this fluid to its resting state [62].

Most of the initial bone adaptation studies focused exclusively on cortical adaptation, since many of the early targeted loading models were unable to be used to assess cancellous bone. However, with the addition of the tibial loading models, the response of cancellous bone could also be probed [46]. Cancellous bone adaptation has been observed in both male and female mice [63], with a response even more robust than was observed in cortical bone [64]. This response in cancellous regions has implications for osteoporosis since cancellous regions are often at greatest risk for fracture [64].

In both cortical and cancellous regions, the strain engendered in the bone tissue due to applied loading plays an integral role in determining its adaptive response. For that reason, the addition of finite element analysis models has been crucial in enabling us to understand the strain field engendered on bone for the various animal loading modalities. Numerous studies have explored strain distributions under the loading regimes, each involving increasingly more sophisticated models [65-72]. Digital image correlation (DIC) has also been used to assess surface strains experimentally. For example, Sztefek et al. measured surface strain using DIC and reported that after tibial loading, the surface strains were reduced and more uniform than before loading [73], suggesting that bone responds to mechanical stimulation as a means of reducing strain.

\section{Intrinsic Factors Influencing Bone Formation Response}

As our understanding of bone adaptation has increased, research in this area has expanded to also include an assessment of various intrinsic factors with the aim of understanding what causes bone to respond as it does. 
The use of genetic animal models has been beneficial, both as a way to understand why some humans might show a better response to loading than others, as well as a means of exploring cellular pathways related to the response. For example, bone adaptation occurs more readily in models of low density bone (C57BL/6J mice) as compared to models of high density bone ( $\mathrm{C} 3 \mathrm{H} / \mathrm{HeJ}$ mice) using targeted tibial loading [74]. Similarly, a genetic study exploring three mouse strains (C3H/He, C57BL/6, and DBA/2) showed decreased responsiveness in the $\mathrm{C} 3 \mathrm{H} / \mathrm{He}$ mice [75]. Together, these studies suggest that genetics contribute to a person's predisposition for high or low bone mass and may also impact their ability to adapt to mechanical stimulation. Genetic mouse models have also been used to tease out some of the underlying molecular pathways involved in the loading response. LRP5-deficient mice were used and showed that the LRP5 mutation was associated with increased response to loading [76], while sclerostindeficient mice demonstrated that long-term sclerostin deficiency can result in increased bone formation [77]. Many studies using germ-line and targeted protein knockouts for estrogen and androgen pathways have investigated the role these pathways play in governing the response to mechanical loading [78-81]. A detailed discussion of these studies is beyond the scope of this paper but the reader is directed to a recent review on the topic [82].

Another major area of exploration has focused on the influence of age. At 26 weeks of age, skeletally mature mice showed reduced sensitivity to mechanical stimulation as compared to actively growing 10 week old mice, even though both young and old mice responded to load. It was suggested that this effect was driven by a decrease in bone tissue deformation [83]. Interestingly, in another study, the strains engendered on bone increased with age due to cortical thinning as assessed experimentally and with a finite element model [66]. This disparity might be driven by the fact that the second study used mice at 5 , 12 and 22 months of age, versus at $\sim 2.5$ and 6 months of age as was the case in the first study. Others have shown that pre- and peri-menarche mice have a greater response to loading that skeletally-mature animals [84]. In yet another study that explored the role of loading in young (10 week) and old (26 weeks) mice at either the same strain level or the same load level, it was found that the same load level (which was a higher 
strain level) was required in the old mice to observe an adaptive effect [85]. Clearly, more work is needed to clarify the impacts that age has on bone's adaptive response.

\section{Mechanical Stimulation in Pre-clinical Assessment}

The use of animal disease models has enabled pre-clinical assessment of the effect of loading in the context of disease. For example, tibial loading was able to prevent bone loss after orchidectomy [86]. In addition, there has been an increase in the exploration of combination treatments, through which is has been observed that loading can synergistically improve the effect of drug treatments such as parathyroid hormone [87] and tamoxifen [88], but not fulvestrant [88]. These studies, and more, have profoundly impacted our understanding of mechanical stimulation. However, as will be discussed in the next section, we must be careful to not confuse improved bone mass with decreased fracture risk.

\section{BONE QUALITY VERSUS BONE QUANTITY}

Much of the focus of the above studies has been in understanding what triggers a bone formation response, with outcomes typically restricted to bone formation rate, bone mass, and bone mineral density. While these studies have been beneficial in increasing our understanding of what drives bone formation, they beg the question as to the importance of increased bone mass in relation to decreased fracture risk. For example, while BMD is a good predictor of fracture risk, other components of bone strength make it difficult for BMD alone to assess fracture $[89,90]$. Thus, if the ultimate goal is to decrease fracture risk in patients with compromised bone structure, we must be sure that the treatments (exercise, targeted loading, etc.) not only positively impact bone mass, but also bone mechanical integrity. If we are merely increasing bone mass without improving mechanical integrity, we are not achieving our end goal. This idea was demonstrated in a recent study by Main et al. which showed that load-induced changes in bone stiffness did not reflect changes in cross-sectional geometry after 2 weeks of loading in mice [84]. 
While bone mass alone should not be the end all assessment to reduce fracture, increased bone mass is still a good outcome. This makes intuitive sense since something that is larger usually requires a greater force to break. Take, for example, a pencil and a tree branch. Both may be made from the same wood, but experience informs us that the pencil will be easier to break (i.e. breaking it will require less force). For bone, similar principles apply. In terms of mechanics, a greater cross-sectional area will decrease tissue-level stress (the force experienced by the tissue itself) by distributing a given force over more material and thus, decrease the risk of fracture. A redistribution of the tissue can also decrease stresses with no change in tissue mass required. However, as mentioned above, bone mineral density and bone mass incompletely predict fracture risk, suggesting that there is more to the story (i.e. the ill-defined term bone quality).

Bone quality, in essence, is the ability of the bone tissue itself to resist load, without regard for its mass and structural morphology. It can be related to the inherent states of the two primary components of the bone matrix: hydroxyapatite and Type I collagen. Some measurable contributors to bone quality include chemical composition, mineral crystal size and crystallinity, mineral-matrix interactions, bone tissue density, degree of collagen cross-linking, accumulation of advanced glycation end-products (AGEs), microdamage, and collagen fiber orientation [91-94]. All of these factors can influence toughening mechanisms in bone [95], thus altering its ability to bear load and absorb energy. Some bone diseases result in increased fracture risk due to decreased bone quality. Take, for example, diabetes. Although diabetic patients often have average or increased BMD, they are also considered to be at higher risk of fracture due to the decreased quality of their tissue, generally attributed to an accumulation of AGEs [96].

Thus, an important question to ask regarding bone adaptation to mechanical load is, how are bone quality and tissue-level properties affected?

\section{MECHANICAL STIMULATION AND BONE QUALITY}


In answer to this, recent research has begun to focus on understanding the contributors of bone tissue quality and how they are affected by mechanical loading. Many of the studies show promising effects with respect to the ability of mechanical stimulation to improve bone quality. An interesting example of the quality/quantity conundrum has been shown in swimming rats. Although clinical and pre-clinical studies have suggested that non-load bearing activities such as swimming only result in mild increases (and sometimes even decreases) in bone mineral content and bone mass [97-99], the post-yield mechanical properties of bones from swimming rats were significantly increased as compared to their sedentary controls [100]. Improved post-yield parameters are important in that they can be related to a bone's ability to resist catastrophic failure by dissipating energy through damage accrual. This damage can later be repaired through targeted remodeling. Given the effect on post-yield mechanical properties, the results were attributed to modifications in collagen since post-yield behavior is most often associated with the state of collagen in bone. In support of the ability of exercise to alter collagen, Isaksson et al. demonstrated that following voluntary running in mice, mechanical properties of the bone collagen network were significantly increased [101]. These benefits came without any changes in collagen content, indicating loading-induced improvements to the collagen network itself.

An increase in post-yield parameters has also been observed in treadmill exercised mice in which, after three weeks of running, mice exhibited increased post-yield mechanical behavior as compared to sedentary controls even though there was no change in bone size or shape [34]. These findings suggested that changes in bone quality, and specifically in collagen, were responsible. Interestingly, when mice were subjected to this running protocol for 3 weeks and then allowed 2 additional weeks of latency, the postyield benefits of exercise were maintained while tissue stiffness and strength increased [102]. These changes, which continued after the termination of loading, suggested that the modifications to collagen may require time to mature; hence, the increased strength with the latency period.

Beyond the effects on monotonic mechanical properties, exercise and loading have other effects which can also be related to changes in bone quality. These include effects on fatigue life or the ability of bone to accrue and tolerate damage due to repeated loading in the absence of a repair mechanism (ex vivo). 
One such study of modified fatigue life involved the rat ulnar loading model [103]. Warden, et al. loaded the ulna of rats daily for 7 weeks followed by 92 weeks of detraining to assess changes in bone quality induced by loading as well as the ability to maintain those changes over time. Although BMC values measured using DXA were the same in the loaded and non-loaded limbs after detraining, the structure (minimum moment of inertia) was larger in the loaded group and the fatigue life was significantly increased compared with controls. There were also increases in whole bone (ash content) and localized (phosphateto-protein) mineralization, as well as in the carbonate to protein ratio in the loaded ulnas. Consistent with the increase in mineralization, the exercised ulnas had increased stiffness and strength, but decreased postyield behavior, suggesting a more brittle bone. However, despite the increase in brittleness, the increase in fatigue life suggests that the bone was still better able to resist fatigue loading-induced failure, likely through modification in the bone's organic phase (i.e. collagen).

A loading-induced improvement in fatigue life was also observed in a study by Kohn, et al. [104]. Using 16-week old male mice, 3 weeks of treadmill running significantly improved tissue strength and fatigue resistance without changes in bone size. Specifically, tibiae from control and exercised mice had similar levels of microcracks and diffuse damage. However, the number of new cracks formed during ex vivo fatigue loading was lessened in exercised bones, suggesting that exercise made the bones more resistant to damage accrual during fatigue. In sedentary mice, fatigue loading altered the mineral-matrix ratio and increased the disorder of the secondary structure of collagen in bone. These results were not observed in exercised mice, indicating that the exercised bones were better able to resist damage to the collagen matrix. Given the lack of changes in bone size (similar to what was seen in the ulnar loading study above, [103]), these results all suggest a direct effect of loading on bone tissue quality, potentially due to changes in collagen specifically.

Although studies of mechanical stimulation on bone quality have shown promising results, not all effects have been positive. Mosekilde, et al. [105] showed that 6 months of treadmill running in rats resulted in increased BV/TV and increased cross-sectional area, but no mechanical improvements in the vertebrae. In addition, the femoral midshaft had increased cortical thickness, but no change in ash content, collagen 
content, apparent density, or mechanical properties. Some of this seeming disparity in results might be driven by the difference in pre-yield and post-yield parameters. Namely, many of the positive effects of loading noted in the above paragraphs have been in either post-yield properties or fatigue parameters, neither of which were addressed in this study. The discussion of pre- and post-yield properties raises another concern. Although many have demonstrated increases in post-yield parameters, those increases are often accompanied by decreases in pre-yield mechanical properties [100, 34]. The decrease in pre-yield mechanical properties could be ameliorated by an additional period of latency [102]. However, the reason for this alteration and the role that pre-yield and post-yield parameters play in ultimately determining fracture resistance remains to be elucidated. Altogether, although many of the studies show positive qualitybased effects of mechanical stimulation, not all studies do, and due to the paucity of information on this topic, the reasons for these discrepancies are not clear.

\section{CONCLUSION}

Mechanical stimulation (whether through exercise or targeted loading modalities) has been shown to beneficially affect bone mass. However, we must be certain that these effects also contribute to improved bone quality and ultimately, to decreased fracture risk. Recent studies have shown mostly positive results, suggesting that loading may cause quality-based changes in bone. However, there have also been several studies that show opposite trends. For that reason, future research is needed to assess specific components

of loading that may either contribute to or prevent quality-based improvements to bone so that ultimately, an understanding of how to improve both quantity and quality can be achieved.

\section{COMPLIANCE WITH ETHICAL STANDARDS}

Funding: This study was funded by: K25-AR067221-01A1

Conflict of Interest: The authors have no conflicts of interest to disclose. 
Ethical approval: This article does not contain any studies with human participants or animals performed by any of the authors. 


\section{REFERENCES}

1. Wolff J. Ueber die innere Architectur der Knochen und ihre Bedeutung für die Frage vom Knochenwachsthum. Archiv für pathologische Anatomie und Physiologie und für klinische Medicin. 1870;50(3):389-450.

2. Koch J. The Laws of Bone Architecture. American Journal of Anatomy. 1917;21(177).

3. Meyer G. Die architektur der spongiosa, archief fur den anatomischen und physiologischen. Wissenschaften im Medicin. 1867;27(4):1389-94.

4. Frost H. The mechanostat: a proposed pathogenetic mechanism of osteoporoses and the bone mass effects of mechanical and nonmechanical agents. Bone and Mineral. 1987;2(2).

5. Rubin CT, Lanyon LE. Osteoregulatory nature of mechanical stimuli: function as a determinant for adaptive remodeling in bone. Journal of Orthopaedic Research. 1987;5(2):300-10.

6. Krahl H, Michaelis U, Pieper H-G, Quack G, Montag M. Stimulation of Bone Growth Through Sports A Radiologic Investigation of the Upper Extremities in Professional Tennis Players. The American journal of sports medicine. 1994;22(6):751-7.

7. Kelley GA, Kelley KS. Exercise and bone mineral density at the femoral neck in postmenopausal women: A meta-analysis of controlled clinical trials with individual patient data. American Journal of Obstetrics and Gynecology. 2006;194(3):760-7.

8. Huddleston AL, Rockwell D, Kulund DN, Harrison RB. Bone mass in lifetime tennis athletes. JAMA. 1980;244(10):1107-9.

9. Warden SJ, Mantila Roosa SM, Kersh ME, Hurd AL, Fleisig GS, Pandy MG et al. Physical activity when young provides lifelong benefits to cortical bone size and strength in men. Proceedings of the National Academy of Sciences. 2014;111(14):5337-42.

10. Dalen N, Olsson KE. Bone mineral content and physical activity. Acta Orthop Scand. 1974;45(2):170-4.

11. Wolman RL, Faulmann L, Clark P, Hesp R, Harries MG. Different training patterns and bone mineral density of the femoral shaft in elite, female athletes. Ann Rheum Dis. 1991;50(7):487-9.

12. Brewer V, Meyer BM, Keele MS, Upton SJ, Hagan RD. Role of exercise in prevention of involutional bone loss. Med Sci Sports Exerc. 1983;15(6):445-9.

13. Fuchs RK, Bauer JJ, Snow CM. Jumping improves hip and lumbar spine bone mass in prepubescent children: a randomized controlled trial. J Bone Miner Res. 2001;16(1):148-56.

14. Kirchner EM, Lewis RD, O'Connor PJ. Effect of past gymnastics participation on adult bone mass. J Appl Physiol (1985). 1996;80(1):226-32.

15. Snow CM, Williams DP, LaRiviere J, Fuchs RK, Robinson TL. Bone gains and losses follow seasonal training and detraining in gymnasts. Calcif Tissue Int. 2001;69(1):7-12. 
16. Colletti LA, Edwards J, Gordon L, Shary J, Bell NH. The effects of muscle-building exercise on bone mineral density of the radius, spine, and hip in young men. Calcif Tissue Int. 1989;45(1):12-4.

17. Jacobson PC, Beaver W, Grubb SA, Taft TN, Talmage RV. Bone density in women: college athletes and older athletic women. J Orthop Res. 1984;2(4):328-32.

18. Orwoll ES, Ferar J, Oviatt SK, McClung MR, Huntington K. The relationship of swimming exercise to bone mass in men and women. Arch Intern Med. 1989;149(10):2197-200.

19. Courteix D, Lespessailles E, Peres SL, Obert P, Germain P, Benhamou CL. Effect of physical training on bone mineral density in prepubertal girls: a comparative study between impact-loading and nonimpact-loading sports. Osteoporos Int. 1998;8(2):152-8.

20. Duncan CS, Blimkie CJ, Cowell CT, Burke ST, Briody JN, Howman-Giles R. Bone mineral density in adolescent female athletes: relationship to exercise type and muscle strength. Med Sci Sports Exerc. 2002;34(2):286-94.

21. Kannus P, Haapasalo H, Sankelo M, Sievanen H, Pasanen M, Heinonen A et al. Effect of starting age of physical activity on bone mass in the dominant arm of tennis and squash players. Ann Intern Med. 1995;123(1):27-31.

22. Currey JD. Bones: structure and mechanics. Princeton university press; 2002.

23. Grimm D, Grosse J, Wehland M, Mann V, Reseland JE, Sundaresan A et al. The impact of microgravity on bone in humans. Bone. 2016;87:44-56.

24. Orwoll ES, Adler RA, Amin S, Binkley N, Lewiecki EM, Petak SM et al. Skeletal health in longduration astronauts: nature, assessment, and management recommendations from the NASA Bone Summit. J Bone Miner Res. 2013;28(6):1243-55.

25. Sibonga JD, Cavanagh PR, Lang TF, LeBlanc AD, Schneider VS, Shackelford LC et al. Adaptation of the Skeletal System During Long-Duration Spaceflight. Clinical Reviews in Bone and Mineral Metabolism. 2007;5(4):249-61.

26. Smith SM, Zwart SR, Heer M, Hudson EK, Shackelford L, Morgan JL. Men and women in space: bone loss and kidney stone risk after long-duration spaceflight. J Bone Miner Res. 2014;29(7):1639-45.

27. LeBlanc AD, Spector ER, Evans HJ, Sibonga JD. Skeletal responses to space flight and the bed rest analog: a review. J Musculoskelet Neuronal Interact. 2007;7(1):33-47.

28. LeBlanc A, Schneider V, Shackelford L, West S, Oganov V, Bakulin A et al. Bone mineral and lean tissue loss after long duration space flight. J Musculoskelet Neuronal Interact. 2000;1(2):157-60.

29. Lang T, LeBlanc A, Evans H, Lu Y, Genant H, Yu A. Cortical and trabecular bone mineral loss from the spine and hip in long-duration spaceflight. J Bone Miner Res. 2004;19(6):1006-12.

30. Pavy-Le Traon A, Heer M, Narici MV, Rittweger J, Vernikos J. From space to Earth: advances in human physiology from 20 years of bed rest studies (1986-2006). Eur J Appl Physiol. 2007;101(2):14394. 
31. Hargens AR, Vico L. Long-duration bed rest as an analog to microgravity. Journal of Applied Physiology. 2016;120(8):891-903.

32. Lanyon L, Skerry T. Perspective: Postmenopausal Osteoporosis as a Failure of Bone's Adaptation to Functional Loading: A Hypothesis*. Journal of Bone and Mineral Research. 2001;16(11):1937-47.

33. . Bone Health and Osteoporosis: A Report of the Surgeon General. Reports of the Surgeon General. Rockville (MD)2004.

34. Wallace JM, Rajachar RM, Allen MR, Bloomfield SA, Robey PG, Young MF et al. Exercise-Induced Changes in the Cortical Bone of Growing Mice Are Bone and Gender Specific. Bone. 2007;40(4):1120-7.

35. Iwamoto J, Yeh JK, Aloia JF. Differential effect of treadmill exercise on three cancellous bone sites in the young growing rat. Bone. 1999;24(3):163-9.

36. Umemura Y, Ishiko T, Yamauchi T, Kurono M, Mashiko S. Five Jumps per Day Increase Bone Mass and Breaking Force in Rats. Journal of Bone and Mineral Research. 1997;12(9):1480-5.

37. Huang TH, Lin SC, Chang FL, Hsieh SS, Liu SH, Yang RS. Effects of different exercise modes on mineralization, structure, and biomechanical properties of growing bone. Journal of Applied Physiology. 2003;95(1):300-7.

38. Hart KJ, Shaw JM, Vajda E, Hegsted M, Miller SC. Swim-trained rats have greater bone mass, density, strength, and dynamics. Journal of Applied Physiology. 2001;91(4):1663-8.

39. Notomi T, Okimoto N, Okazaki Y, Tanaka Y, Nakamura T, Suzuki M. Effects of Tower Climbing Exercise on Bone Mass, Strength, and Turnover in Growing Rats. Journal of Bone and Mineral Research. 2001;16(1):166-74.

40. Mori T, Okimoto N, Sakai A, Okazaki Y, Nakura N, Notomi T et al. Climbing Exercise Increases Bone Mass and Trabecular Bone Turnover Through Transient Regulation of Marrow Osteogenic and Osteoclastogenic Potentials in Mice. Journal of Bone and Mineral Research. 2003;18(11):2002-9.

41. Rubin CT, Lanyon L. Regulation of bone formation by applied dynamic loads. The Journal of Bone \& Joint Surgery. 1984;66(3):397-402.

42. Turner CH, Akhter MP, Raab DM, Kimmel DB, Recker RR. A noninvasive, in vivo model for studying strain adaptive bone modeling. Bone. 1991;12(2):73-9.

43. Gross TS, Srinivasan S, Liu CC, Clemens TL, Bain SD. Noninvasive Loading of the Murine Tibia: An In Vivo Model for the Study of Mechanotransduction. Journal of Bone and Mineral Research. 2002;17(3):493-501.

44. Torrance AG, Mosley JR, Suswillo RF, Lanyon LE. Noninvasive loading of the rat ulna in vivo induces a strain-related modeling response uncomplicated by trauma or periostal pressure. Calcif Tissue Int. 1994;54(3):241-7.

45. Lee KC, Maxwell A, Lanyon LE. Validation of a technique for studying functional adaptation of the mouse ulna in response to mechanical loading. Bone. 2002;31(3):407-12. 
46. De Souza RL, Matsuura M, Eckstein F, Rawlinson SCF, Lanyon LE, Pitsillides AA. Non-invasive axial loading of mouse tibiae increases cortical bone formation and modifies trabecular organization: A new model to study cortical and cancellous compartments in a single loaded element. Bone.37(6):810-8.

47. Sugiyama T, Price JS, Lanyon LE. Functional adaptation to mechanical loading in both cortical and cancellous bone is controlled locally and is confined to the loaded bones. Bone. 2010;46(2):314-21.

48. Berman AG, Clauser CA, Wunderlin C, Hammond MA, Wallace JM. Structural and mechanical improvements to bone are strain dependent with axial compression of the tibia in female $\mathrm{C} 57 \mathrm{BL} / 6 \mathrm{mice}$. PloS one. 2015;10(6):e0130504.

49. Sample SJ, Collins RJ, Wilson AP, Racette MA, Behan M, Markel MD et al. Systemic effects of ulna loading in male rats during functional adaptation. Journal of Bone and Mineral Research.

2010;25(9):2016-28.

50. Burr DB, Allen MR. Basic and applied bone biology. Amsterdam: Elsevier/Academic Press; 2013.

51. Turner CH, Forwood MR, Rho JY, Yoshikawa T. Mechanical loading thresholds for lamellar and woven bone formation. Journal of Bone and Mineral Research. 1994;9(1):87-97.

52. Turner CH, Owan I, Takano Y. Mechanotransduction in bone: role of strain rate. American Journal of Physiology - Endocrinology and Metabolism. 1995;269(3):E438-E42.

53. Hsieh Y-F, Robling AG, Ambrosius WT, Burr DB, Turner CH. Mechanical Loading of Diaphyseal Bone In Vivo: The Strain Threshold for an Osteogenic Response Varies with Location. Journal of Bone and Mineral Research. 2001;16(12):2291-7.

54. Rubin CT, Lanyon LE. Regulation of bone mass by mechanical strain magnitude. Calcified Tissue International. 1985;37(4):411-7

55. Sugiyama T, Meakin LB, Browne WJ, Galea GL, Price JS, Lanyon LE. Bones' adaptive response to mechanical loading is essentially linear between the low strains associated with disuse and the high strains associated with the lamellar/woven bone transition. Journal of Bone and Mineral Research. 2012;27(8):1784-93.

56. Hsieh Y-F, Turner CH. Effects of Loading Frequency on Mechanically Induced Bone Formation. Journal of Bone and Mineral Research. 2001;16(5):918-24.

57. Mosley JR, Lanyon LE. Strain rate as a controlling influence on adaptive modeling in response to dynamic loading of the ulna in growing male rats. Bone. 1998;23(4):313-8.

58. Robling AG, Hinant FM, Burr DB, Turner CH. Improved Bone Structure and Strength After LongTerm Mechanical Loading Is Greatest if Loading Is Separated Into Short Bouts. Journal of Bone and Mineral Research. 2002;17(8):1545-54.

59. Srinivasan S, Weimer DA, Agans SC, Bain SD, Gross TS. Low-Magnitude Mechanical Loading Becomes Osteogenic When Rest Is Inserted Between Each Load Cycle. Journal of Bone and Mineral Research. 2002;17(9):1613-20.

60. Robling AG, Burr DB, Turner CH. Recovery periods restore mechanosensitivity to dynamically loaded bone. Journal of Experimental Biology. 2001;204(19):3389-99. 
61. Batra NN, Li YJ, Yellowley CE, You L, Malone AM, Kim CH et al. Effects of short-term recovery periods on fluid-induced signaling in osteoblastic cells. Journal of Biomechanics.38(9):1909-17.

62. Robling AG, Burr DB, Turner CH. Recovery periods restore mechanosensitivity to dynamically loaded bone. The Journal of experimental biology. 2001;204(Pt 19):3389-99.

63. Lynch ME, Main RP, Xu Q, Walsh DJ, Schaffler MB, Wright TM et al. Cancellous bone adaptation to tibial compression is not sex dependent in growing mice. Journal of Applied Physiology.

2010;109(3):685-91.

64. Fritton JC, Myers ER, Wright TM, van der Meulen MCH. Loading induces site-specific increases in mineral content assessed by microcomputed tomography of the mouse tibia. Bone. 2005;36(6):1030-8.

65. Yang H, Butz KD, Duffy D, Niebur GL, Nauman EA, Main RP. Characterization of cancellous and cortical bone strain in the in vivo mouse tibial loading model using microCT-based finite element analysis. Bone. 2014;66:131-9.

66. Patel TK, Brodt MD, Silva MJ. Experimental and finite element analysis of strains induced by axial tibial compression in young-adult and old female C57Bl/6 mice. J Biomech. 2014;47(2):451-7.

67. Torcasio A, Zhang X, Duyck J, van Lenthe GH. 3D characterization of bone strains in the rat tibia loading model. Biomechanics and Modeling in Mechanobiology. 2012;11(3):403-10.

68. Lu Y, Thiagarajan G, Nicolella DP, Johnson ML. Load/Strain Distribution between Ulna and Radius in the Mouse Forearm Compression Loading Model. Medical engineering \& physics. 2012;34(3):350-6.

69. Akhter MP, Raab DM, Turner CH, Kimmel DB, Recker RR. Characterization of in vivo strain in the rat tibia during external application of a four-point bending load. Journal of Biomechanics.

1992;25(10):1241-6.

70. Dodge T, Wanis M, Ayoub R, Zhao L, Watts NB, Bhattacharya A et al. Mechanical loading, damping, and load-driven bone formation in mouse tibiae. Bone. 2012;51(4):810-8.

71. Stadelmann VA, Hocké J, Verhelle J, Forster V, Merlini F, Terrier A et al. 3D strain map of axially loaded mouse tibia: a numerical analysis validated by experimental measurements. Computer methods in biomechanics and biomedical engineering. 2009;12(1):95-100.

72. Moustafa A, Sugiyama T, Prasad J, Zaman G, Gross T, Lanyon L et al. Mechanical loading-related changes in osteocyte sclerostin expression in mice are more closely associated with the subsequent osteogenic response than the peak strains engendered. Osteoporosis International. 2012;23(4):1225-34.

73. Sztefek P, Vanleene M, Olsson R, Collinson R, Pitsillides AA, Shefelbine S. Using digital image correlation to determine bone surface strains during loading and after adaptation of the mouse tibia. Journal of Biomechanics. 2010;43(4):599-605.

74. Akhter PM, Cullen MD, Pedersen AE, Kimmel BD, Recker RR. Bone Response to In Vivo Mechanical Loading in Two Breeds of Mice. Calcified Tissue International. 1998;63(5):442-9.

75. Robling AG, Turner CH. Mechanotransduction in bone: genetic effects on mechanosensitivity in mice. Bone.31(5):562-9. 
76. Saxon LK, Jackson BF, Sugiyama T, Lanyon LE, Price JS. Analysis of multiple bone responses to graded strains above functional levels, and to disuse, in mice in vivo show that the human Lrp5 G171V High Bone Mass mutation increases the osteogenic response to loading but that lack of Lrp5 activity reduces it. Bone. 2011;49(2):184-93.

77. Morse A, McDonald MM, Kelly NH, Melville KM, Schindeler A, Kramer I et al. Mechanical Load Increases in Bone Formation via a Sclerostin-Independent Pathway. Journal of Bone and Mineral Research. 2014;29(11):2456-67.

78. Lanyon L. Using functional loading to influence bone mass and architecture: objectives, mechanisms, and relationship with estrogen of the mechanically adaptive process in bone. Bone. 1996;18(1):S37-S43.

79. Galea GL, Meakin LB, Sugiyama T, Zebda N, Sunters A, Taipaleenmaki H et al. Estrogen receptor $\alpha$ mediates proliferation of osteoblastic cells stimulated by estrogen and mechanical strain, but their acute down-regulation of the Wnt antagonist Sost is mediated by estrogen receptor $\beta$. Journal of Biological Chemistry. 2013;288(13):9035-48.

80. Castillo AB, Triplett JW, Pavalko FM, Turner CH. Estrogen receptor- $\beta$ regulates mechanical signaling in primary osteoblasts. American Journal of Physiology-Endocrinology and Metabolism. 2014;306(8):E937-E44.

81. Klein-Nulend J, van Oers RF, Bakker AD, Bacabac RG. Bone cell mechanosensitivity, estrogen deficiency, and osteoporosis. Journal of biomechanics. 2015;48(5):855-65.

82. Galea GL, Price JS, Lanyon LE. Estrogen receptors/'roles in the control of mechanically adaptive bone (re) modeling. BoneKEy reports. 2013;2.

83. Willie BM, Birkhold AI, Razi H, Thiele T, Aido M, Kruck B et al. Diminished response to in vivo mechanical loading in trabecular and not cortical bone in adulthood of female C57Bl/6 mice coincides with a reduction in deformation to load. Bone. 2013;55(2):335-46.

84. Main RP, Lynch ME, van der Meulen MCH. Load-induced changes in bone stiffness and cancellous and cortical bone mass following tibial compression diminish with age in female mice. Journal of Experimental Biology. 2014;217(10):1775-83.

85. Lynch ME, Main RP, Xu Q, Schmicker TL, Schaffler MB, Wright TM et al. Tibial compression is anabolic in the adult mouse skeleton despite reduced responsiveness with aging. Bone. 2011;49(3):43946.

86. Fritton JC, Myers ER, Wright TM, van der Meulen MCH. Bone Mass Is Preserved and Cancellous Architecture Altered Due to Cyclic Loading of the Mouse Tibia After Orchidectomy. Journal of Bone and Mineral Research. 2008;23(5):663-71.

87. Sugiyama T, Saxon LK, Zaman G, Moustafa A, Sunters A, Price JS et al. Mechanical loading enhances the anabolic effects of intermittent parathyroid hormone $(1 \& \# x 2013 ; 34)$ on trabecular and cortical bone in mice. Bone.43(2):238-48.

88. Sugiyama T, Galea GL, Lanyon LE, Price JS. Mechanical loading-related bone gain is enhanced by tamoxifen but unaffected by fulvestrant in female mice. Endocrinology. 2010;151(12):5582-90. 
89. Kanis JA. Diagnosis of osteoporosis and assessment of fracture risk. The Lancet.

2002;359(9321):1929-36.

90. Kanis JA, Borgstrom F, De Laet C, Johansson H, Johnell O, Jonsson B et al. Assessment of fracture risk. Osteoporosis International. 2005;16(6):581-9.

91. Van der Meulen M, Jepsen K, Mikić B. Understanding bone strength: size isn't everything. Bone. 2001;29(2):101-4.

92. Donnelly E. Methods for Assessing Bone Quality: A Review. Clinical Orthopaedics and Related Research®. 2011;469(8):2128-38.

93. Judex S, Boyd S, Qin Y-X, Miller L, Müller R, Rubin C. Combining high-resolution micro-computed tomography with material composition to define the quality of bone tissue. Current osteoporosis reports. 2003;1(1):11-9.

94. Seeman E, Delmas PD. Bone quality - the material and structural basis of bone strength and fragility. New England Journal of Medicine. 2006;354(21):2250-61.

95. Launey ME, Buehler MJ, Ritchie RO. On the Mechanistic Origins of Toughness in Bone. Annual Review of Materials Research. 2010;40(1):25-53.

96. Saito M, Marumo K. Collagen cross-links as a determinant of bone quality: a possible explanation for bone fragility in aging, osteoporosis, and diabetes mellitus. Osteoporosis international. 2010;21(2):195214.

97. Taaffe DR, Snow-Harter C, Connolly DA, Robinson TL, Brown MD, Marcus R. Differential effects of swimming versus weight-bearing activity on bone mineral status of eumenorrheic athletes. J Bone Miner Res. 1995;10(4):586-93.

98. Morel J, Combe B, Francisco J, Bernard J. Bone mineral density of 704 amateur sportsmen involved in different physical activities. Osteoporos Int. 2001;12(2):152-7.

99. Bourrin S, Ghaemmaghami F, Vico L, Chappard D, Gharib C, Alexandre C. Effect of a five-week swimming program on rat bone: A histomorphometric study. Calcified Tissue International. 1992;51(2):137-42.

100. Huang T-H, Hsieh SS, Liu S-H, Chang F-L, Lin S-C, Yang R-S. Swimming training increases the post-yield energy of bone in young male rats. Calcified tissue international. 2010;86(2):142-53.

101. Isaksson H, Tolvanen V, Finnilä MA, Iivarinen J, Tuukkanen J, Seppänen K et al. Physical exercise improves properties of bone and its collagen network in growing and maturing mice. Calcified tissue international. 2009;85(3):247-56.

102. Wallace JM, Ron MS, Kohn DH. Short-term exercise in mice increases tibial post-yield mechanical properties while two weeks of latency following exercise increases tissue-level strength. Calcified tissue international. 2009;84(4):297-304.

103. Warden SJ, Fuchs RK, Castillo AB, Nelson IR, Turner CH. Exercise When Young Provides Lifelong Benefits to Bone Structure and Strength. Journal of Bone and Mineral Research.

2007;22(2):251-9. 
104. Kohn DH, Sahar ND, Wallace JM, Golcuk K, Morris MD. Exercise alters mineral and matrix composition in the absence of adding new bone. Cells Tissues Organs. 2009;189(1-4):33-7.

105. Mosekilde L, Danielsen C, Søgaard C, Thorling E. The effect of long-term exercise on vertebral and femoral bone mass, dimensions, and strength—assessed in a rat model. Bone. 1994;15(3):293-301. 